\title{
Dificuldades do aleitamento e o desmame precoce
}

Maria da Conceição Rivemales, M.Sc.*, Ana Caroline Campos Azevedo**, Patrícia Lopes Bastos**

${ }^{*}$ Docente da Universidade Estadual da Bahia (UNEB) e Faculdade de Tecnologia e Ciências (FTC), Orientadora da pesquisa, ${ }^{*}$ Enfermeiras, Faculdade de Tecnologia e Ciências (FTC) Salvador - BA

\section{Resumo}

O estudo tem como objetivo conhecer os problemas que levam a interrupção do aleitamento materno. A abordagem metodológica utilizada foi a revisáo sistemática. As bases de dados eletrônicas utilizadas para a coleta foram Lilacs e Scielo. Do total de publicaçóes encontradas, entre os anos de 1983 a 2005, foram selecionados 12 estudos para constituir a pesquisa. Os resultados evidenciaram que o profissional de saúde deve estar habilitado a preparar a mulher para o aleitamento, respeitando seus valores sócio-culturais, percebendo a importância da comunicação como instrumento de trabalho. Sugerimos que seja feita a utilização do diagnóstico da NANDA com o objetivo de direcionar as açôes de enfermagem para uma resoluçáo ou intervençáo dos possíveis problemas.

Palavras-chave: desmame, aleitamento materno, diagnóstico de enfermagem.

\section{Abstract \\ Breastfeeding difficulties and early weaning}

The objective of this study was to identify the problems that cause early weaning. The methodological approach was the systematic review. The Lilacs and Scielo databases were used for data collection sources. Of the total number of publications found, from 1983 to 2005, 12 studies were selected for the study. The results make evident that health professional should be able to prepare the woman for breastfeeding, respecting their social and cultural values and perceiving the importance of communication as a work tool. We suggested the use of Nanda nursing diagnosis aiming at guiding nursing actions for a decision or intervention of possible problems.

Key-words: weaning, breastfeeding, nursing diagnosis. 


\section{Resumen}

\section{Dificultades de la lactancia materna y el destete precoz}

El estudio tiene como objetivo detectar los problemas que conllevan al destete precoz. La metodología utilizada fue la revisión sistemática. Utilizó como fuentes de búsqueda las bases de consulta: Lilacs y Scielo. Del total de publicaciones encontradas, desde 1983 hasta el 2005, 12 estudios fueron seleccionados para la investigación. Los resultados evidenciaron que el profesional de la salud debe estar capacitado para preparar a la mujer para el amamantamiento, respetando sus valores socioculturales, dándose cuenta de la importancia de la comunicación como instrumento de trabajo. Se sugiere utilizar los diagnósticos de la NANDA con el objetivo de tratar las acciones de enfermería para una resolución o intervención de posibles problemas.

Palabras-clave: destete, lactancia materna, diagnóstico de enfermería.

\section{Introdução}

O ato de amamentar é natural, milenar, sem custo e essencial para a vida dos seres humanos, minimiza a fome, salva vidas e faz o indivíduo crescer não só biologicamente, como também emocionalmente devendo ser de responsabilidade de todos e náo apenas da mulher.

Vivemos em um país em desenvolvimento, com alto índice de mortalidade infantil, muitas vezes causada pela alimentação inadequada na primeira infância, acarretando baixa resistência orgânica e, conseqüentemente, quadros infecciosos irreversíveis, e o não aleitamento materno está entre as causas [1].

Os primeiros anos de vida são decisivos para o estabelecimento de uma boa saúde. Existem necessidades biológicas e psicossociais específicas inerentes ao processo de crescimento e desenvolvimento, as quais precisam ser satisfeitas para garantir a sobrevivência e o desenvolvimento sadio da criança, sendo o aleitamento uma forma de promover essas necessidades [2].

Desse modo, inseridos num contexto que exige por parte dos profissionais da área de saúde, o descobrir e o assumir a responsabilidade de ser o elemento de transformação, se fazem necessárias mudanças enriquecidas com orientaçóes, incentivos e gestos de apoio para que muitas mães adquiram confiança em sua própria capacidade de amamentar.

Este tema tem a intenção de cooperar para o incentivo do aleitamento materno, colaborando para o crescimento e desenvolvimento de crianças, considerando o reflexo do desmame na vida adulta, especialmente nas populaçóes de baixo rendimento econômico, uma vez que o leite materno pode ser uma importante fonte de calorias e de proteínas de alto valor biológico nos seguintes anos de vida.
O aleitamento é uma prática natural e eficaz, um ato cujo sucesso depende de fatores históricos, sócio-culturais e psicológicos da puérpera e do compromisso e conhecimento técnico-científico dos profissionais de saúde envolvidos na promoção, incentivo e apoio ao aleitamento materno [3].

Conforme Burroughs [4], a amamentação precoce é de fundamental importância para o recémnascido, pois permite que este receba o colostro (imunidade passiva) e estimule maior produção de leite. Além de ser alimento mais completo para o bebê, ele acalenta a criança no aspecto psicológico, tem a vantagem técnica por ser operacionalmente simples, é de baixo custo financeiro, protege a mulher quanto ao câncer mamário e ovariano, auxilia na involução uterina, retarda a volta da fertilidade e otimiza a mulher em seu papel de máe.

É recomendação da Organização Mundial de Saúde a amamentação exclusiva durante os primeiros seis meses de vida e parcial até pelo menos o final do primeiro ano de vida, posteriormente a criança deve receber alimentos complementares [5].

Atualmente, sobretudo na sociedade moderna, as mulheres têm poucas oportunidades de obter o aprendizado relacionado à amamentação, já que as fontes tradicionais de aprendizado - mulheres mais experientes da família - foram perdidas à medida que as famílias extensivas foram sendo substituídas pelas famílias nucleadas. Como conseqüência, as mulheres tornam-se máes com pouco ou nenhuma habilidade em levar adiante a amamentação. A grande maioria dos problemas relacionados à amamentação deixa não somente a mãe como também ao lactente mais vulneráveis a apresentarem dificuldades ao longo do processo [6].

Consideramos que o profissional de saúde, em especial o enfermeiro, esteja habilitado a preparar a gestante para o aleitamento, percebendo a importância 
da comunicação como instrumento do processo de trabalho em saúde, utilizando o diagnóstico de enfermagem com o objetivo de direcionar as açóes para uma resolução ou intervençáo adequada, descobrindo novas opçóes, evitando assim, dúvidas, dificuldades e possíveis complicaçóes, investindo em atividades como visitas domiciliares, palestras, grupos de apoio e aconselhamento para incentivo e manutenção do aleitamento materno, a fim de evitar o desmame precoce.

Diante do exposto, foi definido como objeto deste estudo, as dificuldades do aleitamento e o desmame precoce, tendo como objetivo conhecer os problemas que levam a interrupção do aleitamento materno.

\section{Material e métodos}

A revisão sistemática foi a estratégia utilizada para este estudo. As fontes utilizadas foram as bases eletrônicas de dados Lilacs e Scielo, no período entre 1983 a 2005. Foi realizado cruzamento binômio com os unitermos: aleitamento materno $\mathrm{X}$ dificuldades X desmame precoce $\mathrm{X}$ atuação da enfermagem. Um total de 79 publicaçóes foram encontradas, sendo desconsideradas aquelas cujos títulos ou resumos permitiram antecipadamente concluir que não se relacionavam às questóes específicas deste estudo. Dos 12 remanescentes, procedeu-se à busca da publicação completa em bibliotecas especializadas.
Os critérios estabelecidos para a inclusão dos trabalhos foram: artigos publicados entre os anos de 1983 a 2005, procedência nacional, idioma português e que abrangessem diversos fatores envolvidos nas causas do desmame precoce e da atuaçáo da enfermagem. O recorte temporal foi estabelecido, levando em conta que esse período corresponde as duas últimas décadas de produçôes científicas, o que garantiria uma maior abrangência quanto aos artigos publicados sobre a temática.

Foram definidos como critérios de exclusão do estudo publicaçôes sob a forma de livros, manuais, dissertaçôes, teses, editoriais.

Para análise desses estudos foi realizada a leitura exaustiva dos artigos selecionados, de acordo com os critérios de inclusão estabelecidos. Posteriormente, foi verificada a relaçáo entre os resultados das publicaçóes de modo que estas permitissem identificar os problemas que levam a interrupção do aleitamento materno.

\section{Resultados}

A literatura científica levantada mostrou preocupação especial em avaliar a atuaçáo do profissional de enfermagem frente às principais causas do desmame precoce. Os estudos são apresentados conforme a classificação que considera: título, tipo de estudo, resultados e conclusôes.

Quadro 1 - Caracterização dos artigos selecionados no estudo.

\begin{tabular}{|c|c|c|c|}
\hline Estudo & \begin{tabular}{|l|} 
Titulo \\
\end{tabular} & \begin{tabular}{|l|} 
Tipo de estudo \\
\end{tabular} & Resultados \\
\hline E1 [7] & $\begin{array}{l}\text { Evolução do padrão } \\
\text { de aleitamento } \\
\text { materno }\end{array}$ & $\begin{array}{l}\text { Estudo de coor- } \\
\text { te, randomizado }\end{array}$ & $\begin{array}{l}\text { Os resultados apontam para uma apatia do serviço com relação à } \\
\text { promoção do aleitamento materno no período estudado, justifi- } \\
\text { cando plenamente o investimento na promoção da amamentação, } \\
\text { especialmente nas famílias menos privilegiadas. }\end{array}$ \\
\hline E2 [8] & $\begin{array}{l}\text { Fatores que contri- } \\
\text { buem para o desma- } \\
\text { me precoce }\end{array}$ & Exploratório & $\begin{array}{l}\text { A minoria dos sujeitos envolvidos no estudo desconhecia as van- } \\
\text { tagens relativas ao beneficio do aleitamento. Verificou-se que a } \\
\text { maioria das informações, relativas ao aleitamento, foram transmi- } \\
\text { tidas por profissionais de saúde. Sobre as possíveis alterações ma- } \\
\text { márias a maior parte da população desconhecia tais alterações. }\end{array}$ \\
\hline E3 [9] & $\begin{array}{l}\text { O Processo de } \\
\text { comunicação na } \\
\text { promoção do aleita- } \\
\text { mento materno }\end{array}$ & $\operatorname{Rev}$ & $\begin{array}{l}\text { A efetividade das ações voltadas para a recuperação, manutenção } \\
\text { e proteção à saúde da criança está na dependência da adequada } \\
\text { comunicação entre o pessoal de saúde e as mães e/ou responsá- } \\
\text { veis. O profissional de saúde precisa estar preparado para cuidar } \\
\text { dessas nutrizes o que inclui a habilidade para comunicar-se. }\end{array}$ \\
\hline E4 [10] & $\begin{array}{l}\text { Intercorrências } \\
\text { mamárias e desma- } \\
\text { me precoce- uma } \\
\text { abordagem comuni- } \\
\text { cacional }\end{array}$ & Exploratório & $\begin{array}{l}\text { O autor considerou como a primeira categoria da análise in- } \\
\text { terpretativa, os modos de pensar e agir sobre a amamentação, } \\
\text { as soluções que procuram para seus problemas, assim como as } \\
\text { soluções oferecidas a elas. Os resultados obtidos propõem o redi- } \\
\text { recionamento das orientações prestadas, tendo como referencial } \\
\text { teórico a educação problematizadora de Paulo Freire. }\end{array}$ \\
\hline
\end{tabular}




\begin{tabular}{|c|c|c|c|}
\hline Estudo & Titulo & Tipo de estudo & Resultados \\
\hline E5 [1 11$]$ & $\begin{array}{l}\text { Fatores que influen- } \\
\text { ciam o desmame } \\
\text { precoce e a exten- } \\
\text { são do aleitamento } \\
\text { materno } \\
\end{array}$ & $\begin{array}{l}\text { Estudo de coor- } \\
\text { te, randomizado }\end{array}$ & $\begin{array}{l}\text { Variáveis demográficas podem constituir preditores relevantes do } \\
\text { sucesso ou insucesso da amamentação natural. Destaca-se, ainda, } \\
\text { que tais variáveis podem ser identificadas durante o período } \\
\text { pré-natal de modo a priorizar as gestantes com alto risco para a } \\
\text { ocorrência do desmame precoce. }\end{array}$ \\
\hline E6 [12] & $\begin{array}{l}\text { Orientações sobre o } \\
\text { aleitamento materno } \\
\text { inseridas na prática } \\
\text { do cuidado pré-natal } \\
\text { no Brasil }\end{array}$ & Revisão & $\begin{array}{l}\text { Os dados do estudo revelaram que as mulheres declararam } \\
\text { desconhecer se há benefícios na amamentação e que não foram } \\
\text { recebidas informações sobre aleitamento materno no pré-natal. }\end{array}$ \\
\hline E7 [13] & $\begin{array}{l}\text { Aleitamento materno: } \\
\text { uma abordagem } \\
\text { sobre o papel do en- } \\
\text { fermeiro no pós-parto }\end{array}$ & Exploratório & $\begin{array}{l}\text { A atuação do enfermeiro na promoção, no incentivo e apoio ao } \\
\text { aleitamento materno foi mais expressiva e efetiva na maternidade } \\
\text { que apresenta filosofia, estrutura física e equipe multiprofissional } \\
\text { de referência no parto humanizado. }\end{array}$ \\
\hline E8 [14] & $\begin{array}{l}\text { Conhecimento de } \\
\text { mães sobre ama- } \\
\text { mentação }\end{array}$ & Exploratório & $\begin{array}{l}\text { As mães que participaram do estudo referiram que: a informação } \\
\text { e estímulo à amamentação foram pouco referidos no período pré- } \\
\text { natal; elas não possuem conhecimento ou possuem conhecimen- } \\
\text { tos incompletos ou incorretos quanto à higiene das mamas, me- } \\
\text { didas de estímulo à lactação, ingurgitamento mamário e fissuras } \\
\text { de mamilo; elas possuem algum conhecimento sobre aleitamento } \\
\text { materno exclusivo, inexistência de leite materno fraco, freqüência e } \\
\text { duração das mamadas, importância e prejuízos da amamentação. }\end{array}$ \\
\hline E9 [15] & $\begin{array}{l}\text { Revisitando o desma- } \\
\text { me precoce atra- } \\
\text { vés de recortes da } \\
\text { história }\end{array}$ & Revisão & $\begin{array}{l}\text { Conseqüências do desmame precoce para o bebê: crianças des- } \\
\text { mamadas precocemente apresentam maior índice de internação } \\
\text { hospitalar por infecções respiratórias e gastrintestinais. Motivos do } \\
\text { desmame: não existem causas isoladas para estabelecer o curso } \\
\text { da amamentação, mas, sim, relação de fatores associados entre a } \\
\text { mãe, o recém-nascido e o contexto em que eles se encontram em } \\
\text { uma dada dimensão espaço-temporal. }\end{array}$ \\
\hline E10 [16] & $\begin{array}{l}\text { Amamentação: cren- } \\
\text { ças e mitos }\end{array}$ & Exp & $\begin{array}{l}\text { É importante que o profissional de saúde sinta-se responsável } \\
\text { pelos casos de desmame precoce em mães sob sua orientação e } \\
\text { que busque a razão de cada caso de insucesso, refletindo sobre } \\
\text { o que poderia ter feito a mais e melhor. Respeitar, aceitar, ter em- } \\
\text { patia e compreender a mãe constituem atitudes que facilitarão a } \\
\text { resolução dos problemas, facilitando assim o estabelecimento dos } \\
\text { importantes vínculos entre os pais e o bebê. }\end{array}$ \\
\hline E11 [17] & $\begin{array}{l}\text { Educação em saúde } \\
\text { na prevenção do } \\
\text { risco de desmame } \\
\text { precoce }\end{array}$ & Exploratório & $\begin{array}{l}\text { A idade materna representa a variável mais discriminadora no que } \\
\text { respeita à duração do aleitamento natural, o intervalo intergesta- } \\
\text { cional representa a variável mais discriminadora no que respeita } \\
\text { à duração do aleitamento natural e a escolaridade representa a } \\
\text { variável mais discriminadora no que respeita à duração do aleita- } \\
\text { mento natural. }\end{array}$ \\
\hline E12 [18] & $\begin{array}{l}\text { Utilização do diag- } \\
\text { nóstico de enferma- } \\
\text { gem segundo a clas- } \\
\text { sificação da NANDA, } \\
\text { para a sistematiza- } \\
\text { ção da assistência } \\
\text { de enfermagem em } \\
\text { aleitamento materno }\end{array}$ & Exploratório & $\begin{array}{l}\text { Das } 12 \text { mulheres que participaram da pesquisa } 100 \% \text { se enqua- } \\
\text { dravam no diagnóstico déficit de conhecimento, } 75 \% \text { distúrbio no } \\
\text { padrão do sono, } 75 \% \text { alteração no padrão de sexualidade, } 66,6 \% \\
\text { amamentação ineficaz e mobilidade física prejudicada, } 58,3 \% \\
\text { fadiga, 33,3\% ansiedade, 16,6\% medo, potencial para prejuízo } \\
\text { da integridade da pele, potencial para infecção, e alteração no } \\
\text { processo familiar, e 8,3\% potencial para maternidade alterada } \\
\text { e conflito no desempenho de papéis dos pais. Pode-se perceber } \\
\text { que o aleitamento materno não pode ser voltado somente para os } \\
\text { aspectos biológicos, mas também, para os sociais e psicológicos. }\end{array}$ \\
\hline
\end{tabular}


Do total de artigos selecionados foi verificado que quanto ao tipo do estudo: dois foram do tipo coorte randomizado, oito foram estudos exploratórios e três foram artigos de revisão.

Apesar de a maioria dos artigos (oito), terem sido publicados em periódicos específicos da enfermagem, somente dois deles [13,18] trataram especificamente da atuação da enfermeira no aleitamento. Seis artigos $[7,8,10,11,15,16]$ abordaram os problemas que levaram ao desmame precoce e outros quatro $[9,12,14,17]$ discutiram a importância da educação em saúde para a adesão ao aleitamento exclusivo.

Quanto à distribuição dos artigos incluídos no estudo de acordo com o ano de publicação, foi selecionado um artigo nos anos de 1983, 1993, 1997, 2000, 2004 e 2006 e dois artigos nos anos de 2002, 2005 e 2007, totalizando 12 publicações.

De acordo com o local de publicação, os artigos selecionados foram agrupados segundo regióes geográficas brasileiras:

Tabela I - Distribuição dos artigos selecionados segundo local de publicação agrupado segundo região.

\begin{tabular}{ll}
\hline Região & Número de artigos \\
\hline Norte & - \\
Nordeste & - \\
Centro-oeste & 02 \\
Sul & 02 \\
Sudeste & 08 \\
Total & 12 \\
\hline
\end{tabular}

Fonte: Elaborado pelas autoras com base nos dados bibliográficos, 2008.

A regiāo Sudeste teve maior destaque devido ao maior número de publicaçóes, 08 artigos dos 12 selecionados, seguida da regiáo Sul e Centro-Oeste, cada uma com 02 artigos publicados. Nenhum dos artigos selecionados foi publicado na região Norte e Nordeste.

As publicações incluídas no estudo foram extraídas dos seguintes periódicos: Revista Latino Americana de Enfermagem (três artigos), Escola Anna Nery Revista de Enfermagem (um dos artigos), Revista Eletrônica de Enfermagem (dois dos artigos), Revista Gaúcha de Enfermagem (um dos artigos), Revista Cogitare em Enfermagem (um dos artigos), Revista de Saúde Pública (dois dos artigos), Revista Estudos de Psicologia (um dos artigos) e Revista Fafibe On line (um dos artigos).

\section{Discussão}

O baixo nível de renda já é conhecido fator relacionado com prevalência e duração do aleitamento materno. Em áreas mais desenvolvidas, as mulheres de maior nível educacional e econômico amamentam mais nos primeiros meses e esse grupo é o primeiro a valorizar o aleitamento materno, retornando a essa prática.

$\mathrm{O}$ acesso a uma maior disponibilidade de renda pode constituir-se numa proteção contra os processos mórbidos, que desempenham, ao lado da falta de nutrientes, um importante papel na etiologia da desnutrição nos primeiros meses de vida. Em contrapartida o E5 aponta que as mães que vivem em situação de miséria amamentam por mais tempo já que se trata de uma prática que poderá garantir a saúde do bebê sem gasto financeiro por parte da família.

A mulher, cuja importância social relacionavase predominantemente a sua capacidade de gerar força produtiva, passou a ser impelida a contribuir de maneira direta na renda familiar e, assim, foi obrigada a assumir o ônus de uma tripla jornada: mãe, dona de casa, e trabalhadora remunerada. $\mathrm{O}$ fato de as mesmas precisarem se ausentar para retomada do trabalho pode levar a interrupção da amamentação ou pode haver a introduçáo de alimentos complementares contribuindo assim com o desmame precoce.

Ao comparar a idade das mães, nos estudos analisados, foi observado que a maioria das mulheres entrevistadas tinha entre 15 e 19 anos, observando-se que a faixa etária predominante é a de adolescentes.

Podemos inferir que neste período da vida a pessoa vivencia ajustamento social e psicológico, levando a uma crise, pois mudanças no auto-conceito e na percepção do mundo são provocadas, podendo sofrer maiores influências sociais na decisão de amamentar ou náo a sua criança e no período que irá aleitar de forma exclusiva.

No que diz respeito ao estado civil, as mulheres que não têm companheiros fixos se tornam também vulneraveis às condiçóes que podem dificultar o aleitamento exclusivo de seu filho, visto que o acúmulo de tarefas domésticas e de cuidados à criança associado a falta de apoio psicológico e social dificultam o desempenho do papel da nutriz.

Os conceitos transmitidos pelos meios de comunicação, tradiçôes, escola, família e outros exer- 
cem influências na tomada de decisão das pessoas e destaca-se ainda que, em um mesmo ambiente social, há uma pluralidade de idéias a respeito de um mesmo tema, sendo muitas delas eventualmente, contraditórias.

As pessoas têm um sistema de crenças e valores que estão profundamente ligados à própria identidade. Todas as pessoas do círculo social e familiar da mulher, durante o pós-parto têm sempre uma orientação para oferecer. As variadas opiniōes, divergentes e convergentes, levam a nutriz a situação embaraçosa de decisão quanto à conduta a ser tomada em relação à amamentação.

Por outro lado, a assistência pré-natal é de suma importância para a saúde da mulher e seu filho. É possível sugerir que a orientaçáo da enfermagem durante o pré-natal seja relevante para os seguintes aspectos: familiarização das gestantes quanto ao papel do aleitamento materno para sua própria saúde e a do bebê; preparação da mama para o ato de amamentar; necessidade de permanência em alojamento conjunto após o parto; e efeitos deletérios do uso de mamadeira, chupeta e outros hábitos orais.

É extremamente necessária a atuação de grupos de incentivo ao aleitamento materno a fim de reforçar o conteúdo explicitado durante o pré-natal, e de disponibilizar apoio psicossocial às mães para solucionar os inúmeros problemas que surgem durante os primeiros dias e meses após o parto.

Quanto ao tipo de parto, foi percebido a partir dos estudos, que a maioria das participantes teve parto normal. Vale ressaltar que o parto natural favorece uma melhor integração mãe-filho, pois não há a separação imediata como ocorre com o cesáreo, e isso vem a aumentar o laço afetivo entre ambos fazendo o bebê sentir-se mais amado e seguro.

Os autores observaram que a cesariana foi um fator de risco para o início da lactação, pois esse tipo de parto implicou em um aumento do uso de anestésicos e analgésicos que retardaram o primeiro contato mãe-filho e o estabelecimento da amamentação. Além disso, acarretou uma recuperação mais difícil, gerando maior desconforto físico da mãe ao lidar com o bebê.

Relacionado ao puerpério, é necessária uma comunicação simples e objetiva durante a orientação, o incentivo e o apoio ao aleitamento materno no alojamento conjunto, demonstrando diversas posiçóes, promovendo relaxamento e posicionamento confortável, explicando a fonte dos reflexos da criança e mostrando como isso pode ser usado para ajudar na sucção do recém-nascido.

Os primeiros dias após o parto são cruciais para o aleitamento materno bem sucedido, devendo o enfermeiro estar próximo durante e após o parto, auxiliando as mães nas primeiras mamadas do recém-nascido e esclarecendo suas dúvidas. No momento do puerpério as pressóes pessoais e sociais geram tensôes na mulher que podem dificultar sua tomada de decisão para a prática do aleitamento, como inibi-la ou rejeitá-la, buscando formas mais fáceis de alimentar o bebê sem passar pelas adaptações e dificuldades iniciais que possam surgir no ato de amamentar.

Sabe-se que praticamente todas as mulheres têm possibilidades biológicas para amamentar, ou melhor, de começar a amamentar. Porém, após o início, outra ordem de problemas pode acontecer, tais como o ingurgitamento mamário, mamilos doloridos, mastite entre outros que precisam ser solucionados para que haja sucesso no aleitamento.

Por outro lado, o bebê pode apresentar problemas relacionados à sucção incorreta, pega da aréola inadequada, sendo que nesses casos os bebês podem não estar sendo bem posicionados, não abrir a boca suficientemente ou ter recebido bicos artificiais ou chupetas.

Assim, visando à superação dessas dificuldades, justifica-se o desenvolvimento de uma relação interpessoal, fundamentada nessas atitudes e habilidades de comunicaçáo, a fim de promover na nutriz autonomia crescente, no sentido de torná-la apta a explorar e identificar o que se passa consigo mesma.

\section{Conclusão}

Observamos que há inúmeros fatores que podem contribuir para o sucesso ou fracasso do aleitamento materno. Quanto às variáveis que influenciam o desmame, notamos que as razóes alegadas para o insucesso do aleitamento materno estão diretamente associadas aos fatores socioeconômicos e demográficos, já que a mulher frente às dificuldades relacionadas as condiçóes socioeconômicas e a falta de apoio familiar e profissional, tornam-se vulneráveis ao desmame.

É importante que o profissional de saúde, dando enfoque à equipe de enfermagem, sinta-se responsável pelos casos de desmame precoce em mães sob sua orientação e que busque a razão de cada 
caso de insucesso, refletindo sobre o que poderia ter feito a mais e melhor.

Desta forma, sugerimos, que a enfermeira esteja habilitada a preparar a gestante para o aleitamento, percebendo a importância da comunicação como instrumento do processo de trabalho em saúde, utilizando o diagnóstico de enfermagem baseado na NANDA (North American Nursing Diagnosis Association).

Nesse contexto, as açóes de enfermagem devem estar direcionadas para uma resolução/intervenção adequada, descobrindo novas opções a fim de evitar dúvidas, dificuldades e possíveis complicações, investindo em atividades como visitas domiciliares, palestras, grupos de apoio e aconselhamento para incentivo e manutenção do aleitamento materno, a fim de evitar o desmame precoce.

Se faz mister incentivar mais publicaçóes $\mathrm{da}$ enfermagem relativas a atuação da enfermeira frente ao desmame precoce, tendo em vista que foram identificados somente três publicaçóes dentre os artigos incluídos neste estudo.

Sabendo que a enfermeira assiste a mulher durante a gestação, parto e puérperio, é imprescindível que as orientaçóes fornecidas quanto à importância do aleitamento materno sejam de qualidade e esclarecedoras.

Por outro lado, é necessário que a enfermeira esteja atenta aos fatores que podem levar as mulheres a desistirem do aleitamento, devendo atuar no sentido de identificar tais problemas e encorajar essas mulheres na continuidade do aleitamento exclusivo.

\section{Referências}

1. Silva IA. Amamentar: uma questão de assumir riscos ou garantir benefícios. Sáo Paulo: Robe; 1997. p.257-9.

2. Duncan B. Medicina ambulatorial: Condutas clínicas em atenção primária. 2a ed. Porto Alegre: Artes Médicas; 1996.

3. Lana APB. O livro de estímulo à amamentação. São Paulo: Atheneu; 2001.
4. Burroughs A. Uma introdução à enfermagem materna. 6a ed. Porto Alegre: Artes Médicas; 1995.

5. Organização Mundial de Saúde (OMS). Fatores de saúde que podem interferir na amamentação. São Paulo: IBFAN Brasil e Instituto de Saúde, OMS, OPAS e Unicef Brasil; 1994.p.39-48.

6. Carvalho RM. O papel da enfermagem no aleitamento materno [online]. [citado 2007 Jul 18]. Disponível em URL: http://www.amamentacao.org.br.htm.

7. Suzane CK, Elsa G, Lulie OS, Jacson LF, Nádia L, Vivien YJ, et al. Evolução do padrão de aleitamento materno. Rev Saúde Pública 2000;34(2):143-8.

8. Mirella TJ, Maria AAM, Shirley KSB, Ana KBP, Rafaelle LO. Fatores que contribuem para o desmame precoce. Esc Anna Nery Rev Enferm 2005;79(1):356-64.

9. Magda AR, Cecília HSS, Maria LORV, Anna MC, Maria RB. O processo de comunicação na promoção do aleitamento materno. Rev Latinoam Enfermagem 2002;10(2):234-8.

10. Machado LV, Larocca LM. Intercorrências mamárias e desmame precoce - uma abordagem comunicacional. Cogitare em Enferm 2004;9(2):89-98.

11. Carrascoza KC, Costa JAL, Moraes ABA. Fatores que influenciam o desmame precoce e a extensão do aleitamento materno. Estudos de Psicologia 2005;22(4):43340.

12. Beleza ACS, Pitangui ACR, Nakano, MAS, Ferreira $\mathrm{CHJ}$. Orientaçóes sobre o aleitamento materno inseridas na prática do cuidado pré-natal no Brasil. Revista Hispeci \& Lema 2006;9:78-80.

13. Nilza A, Aline GF, Cleide GA. Aleitamento materno: uma abordagem sobre o papel do enfermeiro no pósparto. Revista Eletrônica de Enfermagem 2004;6:318.

14. Neusa BOJ, Elisabeth LC, Neuri NK, Rosimery K. Conhecimento de mães sobre amamentação. Rev Gaúch Enferm 1993;14(1):19-24.

15. Ichisato SMT, Shimo AKK. Revisitando o desmame precoce através de recortes da história. Rev Latinoam Enfermagem 2002;10(4):578-85.

16. Vaucher ALI, Durman S. Amamentação: crenças e mitos. Revista Eletrônica de Enfermagem 2005;7(2):20714 .

17. Candeias NMF. Educação em saúde na prevenção do risco de desmame precoce. Rev Saúde Pública 1983;17(2):71-82.

18. Ana CFVA, Maria GRG, Heimar FM. Utilização do diagnóstico de enfermagem segundo a classificação da NANDA, para a sistematização da assistência de enfermagem em aleitamento materno. Rev Latinoam Enfermagem 1997;5(2):49-59. 